which are parametric equations for the 3-cusp hypocycloid generated by rolling a circle of radius $\frac{1}{2}$ around the inside of a circle of radius $\frac{3}{2}$.

D. F. LAWDEN

G. H. LAWDEN

University of Aston in Birmingham

University of Sussex

\title{
Obituary
}

\section{DONALD HENRY HALFPENNY}

Some weeks before the Annual Conference, I had a letter from Donald to say that he was sorry that he did not think that he would be fit enough to come to Dundee. Little did I, or others of us who would thus be deprived of his genial company, realise how final this separation would be, and when the news reached the Conference of his death the previous Friday (April 6), a shadow fell over those gathered there who knew him. We were aware of the coronary trouble which had led to his early retirement from teaching in 1983, and which had afflicted him over recent years (but about which he never complained), but even so, the shock of his death could hardly have been greater.

Unless there is nothing else to say about a person than to record his career, I do not think that the main purpose of an obituary should be to give a detailed C.V. Rather it is, I think, more to the point to assess the person, his character and achievements. Therefore no more than a brief summary of Donald's career is given here, in a paragraph below.

Some people can be conveniently summarised in a single word: a 'character', a 'card', a 'sport', a 'bore', a 'scatterbrain', a 'dillitante', and so on. The word that comes immediately to mind to describe Donald is a 'gentleman'. This is not a word that I would use lightly, and it is one which is much abused and has many shades of meaning. Of Donald I use that word gentleman in its most literal, and its most favourable sense, and I do not think there can be many of those who knew him who would dissent, or who could find a better word. As one colleague has written to me "... the aspect that immediately occurs to me is his depth of kindness. ... his presence inspired a sense of security and well-being because one could be so certain of his essential concern for those about him". And again, his headmaster wrote of "... his emphasis upon standards, the high regard and respect which he showed to old and young, able and less able alike, for his humanity and for his Christian example...."

For an adjective to go with the noun, one could scarcely improve on the word 'cultured'. Donald was, among other things, an enthusiastic and knowledgeable musician, and a keen chess player, combining these with 
contrasting activities in home and garden —an 'engineer at heart' as his wife Muriel described him.

All these qualities and accomplishments not only enriched his contribution as a schoolmaster, but also ensured that he would be held in high respect by both colleagues and pupils.

A brief account of his professional life should include the following. He came to Kings College London as a King's Scholar in 1938, and was awarded First Class in a Mathematics degree which included a component of Physics. The award of a distinction in his Teacher's Diploma in 1942 was an accurate prognostic of his future success. His teaching experience was in three successive schools. In the most recent of these, Vyners School, Ickenham, he was appointed Head of Mathematics from the time the school was established in 1959 until his retirement in 1982. During that time, he saw the school grow from humble beginnings to its full development as a five-form entry comprehensive school, and taught at all levels, besides organising the mathematical teaching, and succeeding in maintaining high academic standards among the able while introducing new courses for those of less ability.

Donald has been a valued member of the Mathematical Association as well as of the London Branch, for nearly 30 years. He has for many years been one of the assistant treasurers of the Association. A regular attender at the annual Conference over many years, usually accompanied by his wife, he leaves a large gap in the Association. His two children Susan and David, both now in their thirties have both inherited his mathematical gifts, and have been seen on many occasions at Conferences. To all the members of Donald's family, the Association offers its sincere sympathy.

\section{Westfield Avenue, Gosforth, Newcastle upon Tyne NE3 4 YH}

F. J. BUDDEN

\section{Correspondence}

\section{The quadratrix and Buffon's needle}

DEAR EDITOR,

Finding connections between apparently unrelated topics in mathematics is one of the many fascinations of the subject. It can also lead to frustration when one is unable to identify, clearly and rigorously, an isomorphism that one intuitively suspects. Some time ago, while teaching a course on the history of mathematics, I came across just such a puzzling connection.

The quadratrix was a curve designed to solve the Ancient Greek problems of Trisecting the Angle and Squaring the Circle. It can be described in the following way. Imagine the line segment $A B$ moving uniformly down the square until it coincides with the base $O C$. At the same time imagine the line segment $O A$ rotating uniformly through $90^{\circ}$ about $O$ until it also coincides with $O C$. If these two motions occur at the same rate (i.e. they both finish at the same time) then the quadratrix is defined as the locus of their points of intersection. This is 